\title{
Theoretical and Numerical Research on V-Cut Parameters and Auxiliary Cuthole Criterion in Tunnelling
}

\author{
Xiaoming Lou $\mathbb{D}^{1,2}$ Bao Wang, ${ }^{1,2}$ En Wu, ${ }^{1,2}$ Mingwu Sun, ${ }^{1,2}$ Ping Zhou, ${ }^{1,2}$ \\ and Zhenchang Wang ${ }^{1,2}$ \\ ${ }^{1}$ College of Zijin Mining, Fuzhou University, Fuzhou 350116, China \\ ${ }^{2}$ Institute of Blasting Technology, Fuzhou University, Fuzhou 350116, China \\ Correspondence should be addressed to Xiaoming Lou; 331261323@qq.com
}

Received 9 December 2019; Revised 17 January 2020; Accepted 18 January 2020; Published 18 February 2020

Academic Editor: Hossein Moayedi

Copyright ( 92020 Xiaoming Lou et al. This is an open access article distributed under the Creative Commons Attribution License, which permits unrestricted use, distribution, and reproduction in any medium, provided the original work is properly cited.

\begin{abstract}
This paper aims at providing a sound theoretical solution to auxiliary central hole and the cutting parameters. For this purpose, the forming mechanism of $\mathrm{V}$-cut cavity for cutting blasting was performed based on the hypothetical rock breaking mechanism of V-cut blasting. A theoretical solution for increasing the critical depth of the auxiliary center cuthole and the criteria for increasing the cuthole diameter of various types of cutholes when the rock attributes, explosive properties, and cuthole dip angle are constant are proposed. (1) If charging length $l_{e}<0.75 \mathrm{H} / \sin \theta$, no auxiliary cuthole is needed. (2) If $0.75 \mathrm{H} / \sin \theta<l_{e}<0.75 \mathrm{H} / \sin \theta+(2 \sim 4) \times 0.1$, a central vertical auxiliary hole is needed. (3) If $0.75 \mathrm{H} / \sin \theta+(2 \sim 4) \times 0.1<l_{e}<0.75$ $\left(H / \sin \theta+H_{i} / \sin \theta_{i}\right)$, a shallow inclined hole is needed. (4) If $l_{e}>0.75\left(H / \sin \theta+H_{i} / \sin \theta_{i}\right)$, both the central vertical cuthole and the shallow inclined cuthole are needed. Meanwhile, the theoretical solution was verified by numerical modelling with ANSYS/LS-DYNA. Moreover, the field implementation of the V-cut and the auxiliary hole effectively improved the blasting effect in both efficiency and economy.
\end{abstract}

\section{Introduction}

During the tunnel excavation of $\mathrm{V}$-cut blasting, the minimum burden of $\mathrm{V}$-cutholes and the rock clamping force are bound to increase with the depth of $\mathrm{V}$-cuthole. However, the rock residues left at the $\mathrm{V}$-cuthole bottom after blasting may result in bulging and even cutting failure. To prevent the bulging phenomenon, the central auxiliary hole has been widely employed to improve the cyclic advancement and reduce the rock clamping force at the hole bottom. For the past decades, much attention has been paid to the blasting mechanism, cutting method, and cutting parameters. But there are still no mature theoretical results to guide field practice. V-cutting is the key to the entire blasting technology. In order to obtain a satisfactory blasting effect, it is obviously very important to theoretically study and determine reasonable V-cut blasting parameters. Scholars at home and abroad have carried out corresponding research in the related fields.
In terms of the cuthole blasting mechanism, $\mathrm{Ma}$ and $\mathrm{An}$ [1] investigated the fracture and fragmentation mechanism of rock blasting with modified LS-DYNA considering the Johnson-Holmquist damage model. Using LS-DYNA software, Wang and Konietzky [2] explored the crack propagation and rock fragmentation in rock masses with free surface but no boundaries. Cho and Kaneko [3] numerically simulated the fragmentation and dynamic fracture of rock under explosion, obtained the dynamic fracture process of rock under different wave pressures, and verified the dynamic failure mechanism of cutholes. Similarly, Zhu et al. [4] modelled the columnar rock with a center hole by the nonlinear dynamic analysis program AUTODYN (Century Dynamics) and examined the fracture and fragmentation mechanism of rock under dynamic blasting loads. Focusing on a rock blasting test, Stepanov [5] discussed the maximum blasting fracture range of two rows of parallel holes. By the dynamic finite-element method, Guo et al. [6] studied the effect of instantaneous unloading on rock fragmentation 
process under blasting. These studies have provided some basic understanding of rock fragmentation mechanism in cut blasting and useful instructions on how to determine the row distance of cutholes.

In terms of the cutting method, Shapiro [7] performed a detailed analysis on different soft rock cutting arrangements (e.g., V-cut, parallel cut, parallel cut compensated with big cuthole, and composite cut), revealing that V-cut outperforms the other arrangements in blasting efficiency when the hole is less than $2.5 \mathrm{~m}$ deep. Soroush et al. [8] analyzed the effect and sensitivity of the hole diameter and tunnel face area on blasting results in different blast models, pointing out that $\mathrm{V}$-cut needed more cutholes than parallel cut in similar conditions. Shan et al. [9] invented the quasiparallel cutting with a center hole, which combines the merits of parallel cut and angled cut, and achieved desirable blasting and economic effects with the cutting arrangement. Shaprio [7] investigated the feasibility of replacing many shallow cutholes with a few deep ones in tunnelling. Over the years, some innovative methods have been developed for cutting blasting. For example, Chen et al. [10] found the shell radial shaped charge effective in cutting blasting, for it can elevate blasting efficiency, boost cyclic advancement, and lower the drifting costs. Combining middle-space charging and toespace charging, Zhang et al. [11] noticed that the cutting effect of vertical large-diameter cutholes is enhanced by central large-diameter cuthole, stage-by-stage cutting blasting, and deck toe-space charging. The novel cutting blasting method boasts high usage of cutholes, big cavity, low chunk rate, even lumpiness, and efficient use of energy. Recently, Kim and Song [12] replaced cutting blasting with abrasive water jet cutting and assessed the control of the ground vibration during tunnelling. According to experimental and numerical results, this new cutting method is more effective than conventional drilling and blasting.

Concerning the effect of the central hole, Xie et al. [13] simulated the parallel cutting with central hole and attributed the fracture formation among adjacent cutholes to the superposition of stress wave and the tension wave reflected by the wall of the central hole. Based on the stress concentration effect of the central hole, Yang et al. [14] studied the parallel cuthole cutting blasting with central holes, revealing that the central hole can reduce blasting vibration, enhance cuthole usage, and ensure blasting smoothness. Liu et al. [15] performed field tests on the stress concentration effect of central hole and proved that the hole enhances rock fragmentation via the reflection of tensile waves and thereby boosts the cyclic advancement. Probing into the blasting effect of 12-hole compound V-cut, Yang et al. [16] proved that the central hole can significantly improve the throwing effect of broken rocks and cuthole usage. Similarly, Qu et al. [17] simulated the cavity formation and propagation of stress wave of parallel cuthole blasting with ANSYS/LSDYNA. It is concluded that the detonation of charged holes caused the interaction between stress wave and the wall of uncharged holes and that the initial rock cracking and displacement to adjacent uncharged holes are the key to cavity formation in the early phase. Through repeated numerical modelling, Gong et al. [18] optimized the cutting parameters for the excavation of Lvshuidong Mine. The main findings of their research include the following: the peak effective stress at the cuthole bottom was $40 \%$ higher in the presence than the absence of a central hole, revealing the importance of the central hole in the formation of cavity bottom; the in situ tests show that the per cycle advancement increased by $31 \% \sim 65 \%$ due to the addition of central cutholes under the conventional blast loads.

In terms of cutting parameters, Shapiro et al. [19] investigated the compensated hole volume of different straight hole cutting methods, laying a good basis for determining the diameter and depth of the supplemental hole. Based on cutting blasting tests, Bezmatemykh et al. [20] put forward the theoretical solutions of minimum burden and the other cutting parameters. Owe and $\mathrm{O}$ [21] employed grey relative analysis to analyze the effects of the parameters like hole depth, dip angles, and hole spacing on the V-cut blasting charged at the bottom. Andrievskii [22] optimized the parameters for drill-and-blast operation chart in mining with direct slot stage cutting. In addition, Qiao et al. [23, 24] research on optimization algorithms, wave transformation, and hybrid model prediction of improved deep learning, Lou et al. $[25,26]$ research on impact pressure on blasthole wall with radial air-decked charge, and so on obviously have better parameter value for blasting parameter optimization.

Despite the extensive research on cutting in tunnelling, there is a severe lack of theoretical or empirical analysis on when to add a central hole. For the need of a systematic understanding of central holes, the implementation of central holes may face numerous challenges during the variation in rock attributes, explosive properties, and/or cuthole depths. This calls for a sound theoretical solution to auxiliary central hole and the cutting parameters.

In light of the above, this paper is based on $\mathrm{V}$-cut blasting rock breaking mechanism hypothesis [27], the relationship between the cutholes parameters is studied, the theoretical formula of each cutholes parameter is deduced, and the addition of an auxiliary center is proposed. Calculation method of critical depth of holes and the theoretical analysis results were verified by numerical simulations. The results show that when the depth of the blasthole or the length of the charge satisfies certain conditions, the addition of a central auxiliary slot can significantly improve the effective dynamic effect of the bottom of the blasting cavity, which is beneficial to the ideal cut blasting depth and cavity shape.

\section{Hypothesis on V-Cut Blasting Mechanism}

The V-cut, consisting of two or more rows of symmetrical oblique holes, helps to form a wedge cavity after blasting. For simplicity, this study mainly focuses on a single $\mathrm{V}$-cut made up of three pairs of inclined holes. The cuthole arrangement in $\mathrm{V}$-cut is presented in Figure 1 , where $H$ is the vertical depth of cuthole, $d_{l}$ is cuthole spacing, $a$ is hole bottom spacing, $b$ is orifice spacing, $E_{i} C_{i}$ and $F_{i} D_{i}$ are charged sections with a length of $l_{e}$, and $A_{i} E_{i}$ and $B_{i} F_{i}$ are uncharged sections with a length of $l_{s}$.

The 3D model of the horizontal single V-cut blasting cavity is displayed in Figure 2. Since the rock masses around 

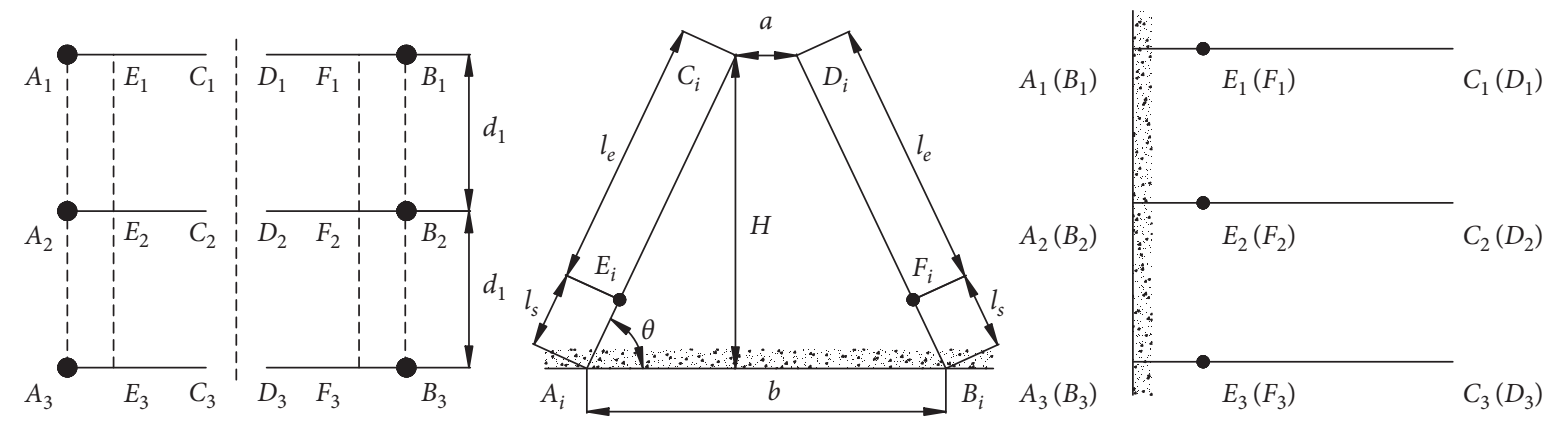

FIgURE 1: Cuthole arrangement in V-cut.

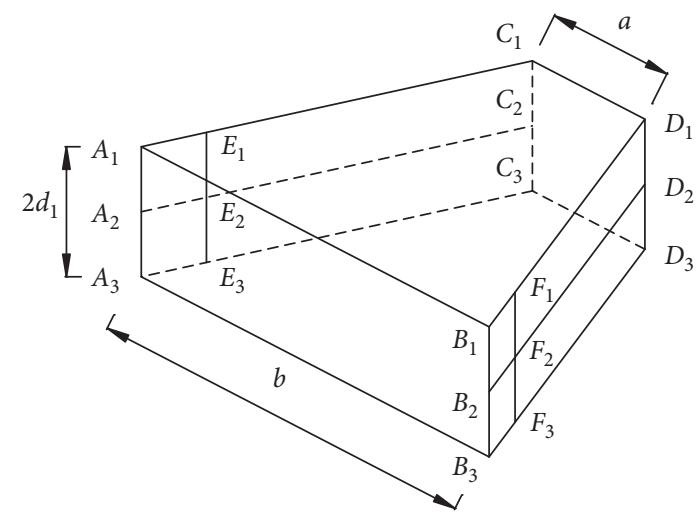

FIgURE 2: 3D model of horizontal single V-cut blasting cavity.

the cutholes are tightly compressed by explosive wave after the blasting of the three pairs of inclined cutholes [28], a broken zone will form under the interaction of adjacent holes and two inclined planes (i.e., $E_{1} C_{1} C_{3} E_{3}$ and $F_{1} D_{1} D_{3} F_{3}$ ) across the same column holes. Considering the inclination between the cuthole and working face, the cuthole detonation will release a force acting on the outside normal direction of the working face. The force will drive the rock away from the cavity area, leaving a shearing effect on surrounding rocks. In this case, the surfaces of $A_{1} B_{1} D_{1} C_{1}$, $A_{3} B_{3} D_{3} C_{3}, A_{1} E_{1} E_{3} A_{3}$, and $B_{1} F_{1} F_{3} B_{3}$ will suffer from shearslip failure. The rocks at the hole bottom will be crushed and cut through due to their small spacing between cuthole bottoms, forming a cut-through face $C_{1} D_{1} D_{3} C_{3}$. In this way, the rock masses in the cavity will be completely separated from surrounding rocks, and a cavity will eventually appear under the throwing effect of the quasistatic pressure of the explosive gas.

\section{Cavity Formation Mechanism}

According to the hypothesis on the V-cut blasting mechanism, a trapezoid cavity will appear only through the separation of surfaces in the cavity (i.e., $A_{1} B_{1} D_{1} C_{1}, A_{3} B_{3} D_{3} C_{3}$, $A_{1} E_{1} E_{3} A_{3}, B_{1} F_{1} F_{3} B_{3}, E_{1} C_{1} C_{3} E_{3}, F_{1} D_{1} D_{3} F_{3}$, and $\left.C_{1} D_{1} D_{3} C_{3}\right)$ from surrounding rock masses. However, the separation mechanism differs from one face to another, depending on the specific location relative to cutholes. In general, surfaces $E_{1} C_{1} C_{3} E_{3}, F_{1} D_{1} D_{3} F_{3}$, and $C_{1} D_{1} D_{3} C_{3}$ are the result of explosive stress wave, while surfaces $A_{1} B_{1} D_{1} C_{1}, A_{3} B_{3} D_{3} C_{3}$,
$A_{1} E_{1} E_{3} A_{3}$, and $B_{1} F_{1} F_{3} B_{3}$ are attributed to the shear failure induced by the explosive force along the normal direction of the working face. Here, it is assumed that every cuthole wall withstands equal initial impact pressure from explosion, and the uncharged sections are filled up with explosive gas, which is distributed uniformly along the internal cuthole wall.

3.1. Cavity Shear Strength. According to the location of each cavity surface, the shear strength of the upper cavity $A_{1} B_{1} D_{1} C_{1}$ equals that of the lower cavity $A_{3} B_{3} D_{3} C_{3}$, and the shear strengths of two inclined planes in uncharged sections $\left(A_{1} E_{1} E_{3} A_{3}\right.$ and $\left.A_{1} E_{1} E_{3} A_{3}\right)$ are the same. Let the rock shear strength be $\tau_{s}$. Then, the shear strength of the upper and lower sides of the cavity and the two inclined planes in uncharged sections can be expressed as

$$
\begin{aligned}
& \tau_{A_{1} C_{1} D_{1} B_{1}}=\tau_{A_{3} C_{3} D_{3} B_{3}}=\frac{\tau_{s}(a+b) H}{2}, \\
& \tau_{A_{1} E_{1} E_{3} A_{3}}=\tau_{B_{1} F_{1} F_{3} B_{3}}=2 \tau_{s} d_{1} l_{s} \sin \theta .
\end{aligned}
$$

For a given dip angle between the cuthole and the free surface, (1) can be rewritten as follows according to the geometric relation:

$$
\tau_{A_{1} C_{1} D_{1} B_{1}}=\tau_{A_{3} C_{3} D_{3} B_{3}}=H \tau_{s}\left(a+\frac{H}{\tan \theta}\right),
$$

whereas the rock fragments in the cavity are thrown out along the normal direction of the free surface, the total shear strength of the minimum burden can be obtained by the relative location of the cavity surface and the free surface:

$$
\tau=2 H \tau_{s}\left(a+\frac{H}{\tan \theta}\right)+4 \tau_{s} d_{1} l_{s} \sin \theta .
$$

3.2. Explosive Force in the Normal Direction of the Free Surface. To ensure the effectiveness of cutting blasting, the explosive force must be strong enough to cause a shear failure on the upper and lower sides of the cavity and on the two inclined planes in uncharged sections. As shown in Figure 3 , after the detonation in cuthole $A_{2} C_{2}$, the horizontal and radial resultant force $F$ of the explosive gas on the hole wall can be expressed as 

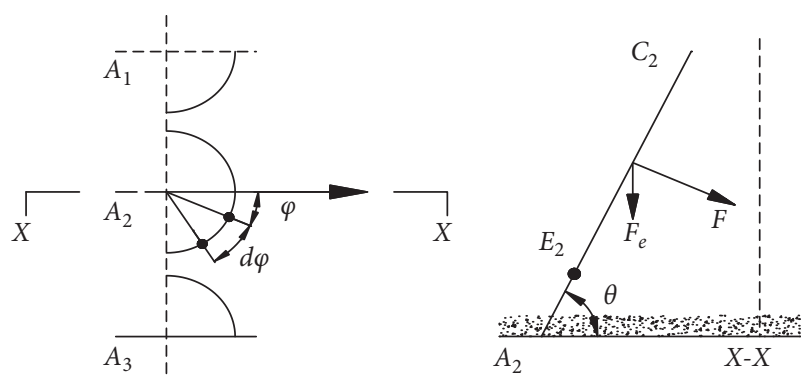

FIGURE 3: Cutting blasting effect.

$$
F=2 \int_{0}^{\pi / 2} P l_{e} r_{a} \cos \varphi d \varphi,
$$

where $P\left(P=\rho_{0} D^{2} / 8\right)$ is the average detonation pressure in the hole; $\rho_{0}$ is the density of explosive; $D$ is the detonation velocity of explosive; $r_{a}$ is the hole radius; and $\varphi$ is the angle between any point and the horizontal radius of the cross section passing through the point.

Due to the symmetrical arrangement of cutholes, the resultant force on the horizontal radius of hole wall $B_{2} D_{2}$ equals that of cuthole $A_{2} C_{2}$. According to Figure 3, the force obtained by (5) is perpendicular to the axis of the cuthole. Since the rocks in the cavity are eventually thrown out along the outer normal direction of the free surface, the effective acting force of the explosive gas is the component along this direction:

$$
F_{e}=2 \cos \theta \int_{0}^{\pi / 2} P l_{e} r_{a} \cos \varphi d \varphi .
$$

For the three pairs of cutholes, the effective forces of the explosive gas on the four corners of the cutholes $\dot{F}_{e}$ account for only a half of that of cutholes in the central row:

$$
\dot{F}_{e}=\cos \theta \int_{0}^{\pi / 2} P l_{e} r_{a} \cos \varphi d \varphi .
$$

Based on (6) and (7), the resultant force of the three pairs of cutholes in the normal direction of the free surface can be obtained as

$$
\sum F_{e}=8 P l_{e} r_{a} \cos \theta
$$

3.3. Cavity Separation Conditions. According to the first strength criterion, the cavity will not appear until the rocks in the cavity reaches an ultimate equilibrium under the quasistatic action of the explosive gas; that is,

$$
\sum F_{e}=\tau
$$

When the shear stresses on the upper and lower end surfaces of the cavity and the two inclined surfaces between the uncharged sections of the blasthole satisfy formula (9), shear-slip surfaces $A_{1} B_{1} D_{1} C_{1}, A_{3} B_{3} D_{3} C_{3}, A_{1} E_{1} E_{3} A_{3}$, and $B_{1} B_{3} F_{3} F_{1}$ can be formed.

\section{Determination of Cutting Parameters}

The important parameters of cutting blasting include cuthole bottom spacing, row spacing, and charge coefficient.
Meanwhile, the critical cuthole depth was introduced as the criterion for the addition of auxiliary central hole. Based on the above theoretical analysis, the parameters of each cuthole are derived as follows.

4.1. Distance between Cutholes and Rows. To determine the row spacing in the cutting, there should be a blasting-induced crack extending across different rows, which separates the rocks in the cavity from surrounding rocks. For the hole bottom spacing, the rock at the cavity bottom must be fully broken, so as to separate from surrounding rocks under the shock wave.

The cuthole spacing is usually calculated by the radius ratio between the crushed zone and the fracture zone caused by the explosion. In general, the hole bottom spacing is twice that of the crushed zone radius, and the row spacing is twice that of the fracture zone radius. Therefore, the hole bottom spacing $a$ and the row spacing $d_{1}$ can be expressed as

$$
\begin{gathered}
a=2 r_{1}, \\
d_{1}=2 r_{2},
\end{gathered}
$$

where $r_{1}$ is the radius of crushed zone; $r_{2}$ is the radius of fracture zone.

In cutting blasting, the rock withstands both tension and compression from all directions. The crushed zone is caused by the compressive stress and the fracture zone is caused by the tensile stress. Thus, the radius of the crushed zone $r_{1}$ and the radius of the fracture zone $r_{2}$ can be expressed as

$$
\begin{aligned}
& r_{1}=\left(\frac{\rho_{0} D^{2} A B}{4 \sqrt{2} \sigma_{c d}}\right)^{1 / \alpha} r_{a}, \\
& r_{1}=\left[\frac{\rho_{0} D^{2} n B}{8 \sqrt{2} \sigma_{c d}}\left(\frac{r_{b}}{r_{a}}\right)^{6}\right]^{1 / \alpha} r_{a},
\end{aligned}
$$

where

$$
\left\{\begin{array}{l}
A=\frac{2 \rho_{m} c_{p}}{\rho_{m} c_{p}+\rho_{0} D} \\
B=\sqrt{\left[(1+\lambda)^{2}-2 \mu_{d}(1-\lambda)^{2}\left(1-\mu_{d}\right)+(1+\lambda)^{2}\right]} \\
\alpha=2+\frac{\mu_{d}}{1-\mu_{d}}
\end{array}\right.
$$

Formulas (11a) and (11b), respectively, indicate the radius of the crushing area under the conditions of coupled charge and uncoupled charge. Among them, $\sigma_{c d}$ is the uniaxial dynamic compressive strength of the rock, $\sigma_{c d}=\sigma_{c} \dot{\varepsilon}^{1 / 3}, \dot{\varepsilon}$ is for the strain rate under load, Hakailehto suggested [29], and desirably $\dot{\varepsilon}=100$.

The crack zone radius $r_{2}$ is obtained as

$$
r_{2}=r_{1}\left(\frac{\sigma_{c d}}{\sigma_{t d}}\right)^{1 / \alpha}
$$


where $\alpha$ is the stress wave attenuation coefficient, $\alpha=2-$ $\mu_{d} /\left(1-\mu_{d}\right)$.

If the dynamic effects of fracture circle and rock strength are ignored, it can be calculated according to formula (14) [30]:

$$
d_{1}=2 r_{a}\left(\frac{\lambda P_{0}}{\sigma_{t d}}\right)^{1 / \alpha}
$$

where $P_{0}$ is the explosive load acting on the wall of the blasthole.

4.2. Distance between Cuthole Bottoms. As with the row distance, too large and too small distance at the bottom of the holes are not conducive to rock fragmentation and throwing. From [31], it can be known that too small distance between hole bottoms may cause explosives to be squeezed and explosion rejection will occur. If the distance between hole bottoms is too large, the intensity of the shock wave will rapidly decay during the propagation process, rocks within the range of the hole bottom cannot be destroyed completely, and it is easy to cause a bulged phenomenon.

When determining distance of the bottom cutholes, it is required that the rock at the bottom of the cut blasting cavity is fully damaged, and the rock at the bottom of the blasthole in the cut blasting cavity can be separated from the cavity wall under the action of a shock wave. For the boundary of the shock waves excited at the bottom of adjacent cutholes, it can be regarded as being on the center line of the cutholes after the two groups of adjacent drug packs are blasted together. Studies have shown that the stress wave will be superimposed between the cutholes and the stress on the connecting line will be strengthened. In order to meet the blasting requirements, the crushed area at the bottom of adjacent cutholes should intersect, and formula (15) can be used to calculate the bottom hole distance $a$ :

$$
a=2 r_{1} \text {. }
$$

4.3. Distance between Cuthole Heads and Inclined Angle. According to the analysis of the formation mechanism of the cut blasting cavity, it can be known that there is a relationship between the distance between cuthole heads and the inclined angle as in formula (16), which affects each other:

$$
b=a+\frac{2 H}{\tan \theta} \text {. }
$$

4.4. Charging Coefficient. The cavity force shows that (9) is the precondition for separating cavity rocks from surrounding rocks. If the charge length le is replaced by the explosive charge coefficient $k$ and then $k$ can be derived as

$$
\begin{aligned}
k & =\frac{l_{e}}{H / \sin \theta}, \\
\sum F_{e} & =\frac{8 k P H r_{b}}{\tan \theta} .
\end{aligned}
$$

Substitute (4) and (16) into (9). Then, the charging coefficient $k$ can be expressed as

$$
k=\frac{\tau_{s}(a \tan \theta+H)}{4 P r_{b}}+\frac{\tau_{s} d_{1} l_{s} \sin \theta \tan \theta}{2 P H r_{b}} .
$$

The charging coefficient $k$ in (17) is applicable to coupled charging, which is difficult to realize in practice. Instead of coupled charging, the uncoupled charging is commonly adopted for blasting. In tunnel blasting, the cuthole is usually $40 \mathrm{~mm}$ in diameter and the cartridge is $32 \mathrm{~mm}$ in diameter. Meanwhile, the charging coefficient $k$ should be greater than 0.75 to ensure the effective stemming and utilization of explosive energy [28]. Hence, (17) can be transformed to

$$
k=\left[\frac{\tau_{s}(a \tan \theta+H)}{4 P r_{b}}+\frac{\tau_{s} d_{1} l_{s} \sin \theta \tan \theta}{2 P H r_{b}}\right] \times\left(\frac{r_{a}}{r_{b}}\right)^{2} .
$$

4.5. Critical Cuthole Depth and Auxiliary Cuthole Criterion. For better drifting footage, the blasting operation usually adopts a high charge coefficient. However, the resulting reduction in stemming length may result in insufficient stemming and the loss of explosive energy. To solve the problem, extra central holes should be added perpendicularly to the free surface, together with some shallow inclined holes in the middle part of the cutting area. The number of additional holes hinges on the charging dosage. Additionally, the depth of the auxiliary central hole is equal to $H$, and only 2 4 sections are charged at the hole bottom. The depth of an additional inclined hole can be expressed as [32]

$$
H_{i}= \begin{cases}\frac{H}{2}+\Delta H, & 10 H \text { is even, } \\ \frac{0.1+H}{2}+\Delta H, & 10 H \text { is odd }\end{cases}
$$

where $\Delta H(\Delta H=0.2 \mathrm{~m})$ is the length of subdrilling.

The critical cuthole depth is defined as the depth when auxiliary cutholes are added to cutting blasting. Since the critical condition for (18) is $k=k_{c}=0.75$ [30], there is

$$
H_{c}=\frac{4 P r_{a} k_{c}}{\tau_{s}}\left(\frac{r_{b}}{r_{a}}\right)^{2}-\frac{d_{1} \sin ^{2} \theta \tan \theta}{2}-a \tan \theta,
$$

where $k_{c}$ is the critical charging coefficient.

Then, the charge quantity for the first cuthole is

$$
Q_{c}=\frac{\rho_{0} \pi r_{a}^{2} k_{c} H}{\sin \theta}
$$

Without changing the rock attributes, explosive properties, and cuthole dip angle, cutholes should be added when the hole depth exceeds the critical value $H_{c}$. Meanwhile, the type of the auxiliary cuthole depends on the charging length:

(1) If charging length $l_{e}<0.75 H / \sin \theta$, no auxiliary cuthole is needed.

(2) If $0.75 H / \sin \theta<l_{e}<0.75 H / \sin \theta+(2 \sim 4) \times 0.1$, a central vertical auxiliary hole is needed.

(3) If $0.75 H / \sin \theta+(2 \sim 4) \times 0.1<l_{e}<0.75\left(H / \sin \theta+H_{i} /\right.$ $\left.\sin \theta_{i}\right)$, a shallow inclined hole is needed.

(4) If $l_{e}>0.75\left(H / \sin \theta+H_{i} / \sin \theta_{i}\right)$, both the central vertical hole and the shallow inclined hole are needed. 


\section{Theoretical Calculation}

Four types of rocks (i.e., shale, sandstone, limestone, and granite) were selected for the theoretical calculation. The physical-mechanical parameters of rocks are presented in Table 1. The 2\# rock emulsion explosive (density: $\rho_{0}=1,300 \mathrm{~kg} / \mathrm{m}^{3}$; detonation velocity $D=4,000 \mathrm{~m} / \mathrm{s}$; length: $300 \mathrm{~mm}$; diameter: $32 \mathrm{~mm}$; weight: $0.3 \mathrm{~kg}$ ) was adopted for the calculation. The critical hole depth of each type of rock at different hole depths and dip angles were obtained according to the theoretical solution (Section 3). Then, the relationships between the critical hole depths and the slope angles of four rocks were determined based on the calculated results in Table 2. As shown in Figure 4, the critical hole depth decreased gradually with the increase of dip angle for all cases.

According to Table 2, the critical cuthole depth-inclined angle relationship curve that can be used for four types of rocks is shown in Figure 4. From Figure 4 and Table 2, it can be seen that as the dynamic compressive strength, tensile strength, and shear strength increase, the critical cuthole depth gradually decreases; as the inclination angle of the cuthole increases, the clamping force decreases; and as the base resistance increases, the critical cuthole depth of the hole gradually decreases. This is consistent with the current theoretical research results and field practice. In addition, taking sandstone as an example, when the inclination angle of the cuthole is 45 degrees, the critical depth of the blasting hole is 3.68 meters, which is also the same as the center hole when the depth of the cuthole is $3.5 \sim 4$ meters when the sandstone tunnel is blasted in practice.

\section{Numerical Simulation}

6.1. Model Building. In light of the hole arrangement in Figure 5, two numerical models (I and II) of the same dimensions (length: $500 \mathrm{~cm}$; width: $300 \mathrm{~cm}$; height: $280 \mathrm{~cm}$ ) were established by ANSYS/LS-DYNA. Six single V-shaped cutholes were arranged in the two models $\left(A_{1} C_{1}, A_{2} C_{2}, A_{3} C_{3}\right.$, $\mathrm{B}_{1} D_{1}, \mathrm{~B}_{2} D_{2}$, and $\left.\mathrm{B}_{3} D_{3}\right)$. The parameters are details as follows: the vertical depth of the cuthole $H_{\mathrm{m} 1}=3 \mathrm{~m}$, the hole diameter $2 r_{\mathrm{a} 1}=40 \mathrm{~mm}$, the dip angle of the hole $\theta_{\mathrm{m} 1}=60^{\circ}$, the row spacing of the cuthole $=80 \mathrm{~cm}$, and the hole bottom spacing $=30 \mathrm{~cm}$.

Model I was designed without any central hole, while model II was added with two central holes vertical to the free surfaces $\left(P_{1} Q_{1} ; P_{2} Q_{2}\right)$ in the middle of the cutting area. The charging lengths for cutholes in models I and II were $2.7 \mathrm{~m}$ and $2.6 \mathrm{~m}$, respectively. The calculation formulas are, respectively, $0.75 H_{\mathrm{m} 1} / \sin \theta_{\mathrm{m} 1}=2.6 \mathrm{~m}$ and $0.75 H_{\mathrm{m} 1} / \sin \theta_{\mathrm{m} 1}+2 \times 0.1=2.8 \mathrm{~m}$. In the meantime, the central holes in model II were also charged $0.3 \mathrm{~m}$ in length and $32 \mathrm{~mm}$ in diameter, with the orifices blocked with stemming. According to the tunnelling environment, the plane of cutholes was set as a free surface, and the other five planes were set as nonreflecting boundaries.

6.2. Selections of Material and State Equation. To improve the accuracy of the numerical simulation, the $*$ MAT-
PLASTIC-KINEMATIC, $*$ MAT-HIGH- EXPLOSIVEBURN, *MAT-NULL, and $*$ MAT-SOIL-AND-FOAM models were adopted to describe the rock mass, the explosive, the air, and stemming materials, respectively. In addition, the state equations of the explosive and the air were modelled by $*$ EOS-JWL and *EOS-LINEAR-POLYNOMAIAL, respectively. The parameters of each material model and its state equation are listed in Tables 3 6. During the calculation, the ALE algorithm was applied for the explosive, the air, and stemming materials, while the Lagrangian algorithm was adopted for the rock mass.

6.3. Simulation Results. To compare the cutting effect of models I and II, especially the morphology of the cavity formed at the bottom of the cutting area, a $0.5 \mathrm{~m}$ section near the hole bottom in the central axis of the cutting area $(\mathrm{GH})$ was selected for monitoring the effective dynamic stress. The monitoring points were arranged along the cuthole wall at an interval of $0.05 \mathrm{~m}$.

Figure 6 illustrates the effective stress contours at different stages after detonation. It can be seen from Figure 6 that, in the initial stage of the explosion of the $\mathrm{V}$-cut blasting hole, the explosion stress wave is cylindrical and propagates outward with the blasthole as the center. The maximum effective stress at the bottom of the blasthole can reach $300 \mathrm{MPa}$ or more, which is much greater than the compressive strength of the rock. Then the rock is crushed. Subsequently, the stress wave continued to propagate outward and superimposed, and the effective stress began to decrease. A saddle-shaped stress isosurface was formed between the V-cut blasting holes, which significantly reduced the compression failure of the rock, indicating that when the rock hardness is greater, the V-cut blasting hole exploded. After that, the rock at the bottom of the trough cavity cannot be fully destroyed; at the same time, due to the large clamping force of the rock at the bottom of the hole, part of the rock mass in the area can be retained. After the central hole is detonated, the stress at the center of the cavity is rapidly increased, and the isoline density is also increased. The blasting of the two central holes plays the role of breaking the rock body that has not fully broken after the $\mathrm{V}$-cut blasting hole detonated. It helps to throw the secondary broken rock body out of the trough cavity and provides more space for broken rock compensation for subsequent blasthole blasting. In addition, after the blasting of the central hole, the stress field at the bottom of the slot cavity is uniformly distributed, with a larger range of action and uniform energy distribution. An approximately rectangular stress concentration area is formed at the bottom of the V-cut blasting cavity. According to the results of numerical simulation calculations, it can be known that the method of undercutting with a central hole is conducive to reducing the occurrence of the bulged phenomenon, thereby forming a larger $\mathrm{V}$-cut blasting cavity volume.

Figure 7 presents the distributions of effective stress within the monitored sections in the two models. As shown in Figure 7, model II has a much higher maximum effective stress of blasting than model I. The dynamic compressive strength of sandstone (the dotted line in Figure 7) was 
TABLE 1: Physical-mechanical parameters of the four types of rocks [28].

\begin{tabular}{lcccccc}
\hline $\begin{array}{l}\text { Rock } \\
\text { name }\end{array}$ & $\begin{array}{c}\text { Density } \\
\left(\mathrm{g} / \mathrm{cm}^{3}\right)\end{array}$ & Poisson ratio & $\begin{array}{c}\text { Longitudinal wave } \\
\text { velocity }(\mathrm{km} / \mathrm{s})\end{array}$ & $\begin{array}{c}\text { Dynamic compressive } \\
\text { strength }(\mathrm{MPa})\end{array}$ & $\begin{array}{c}\text { Dynamic tensile } \\
\text { strength }(\mathrm{MPa})\end{array}$ & $\begin{array}{c}\text { Shear strength } \\
(\mathrm{MPa})\end{array}$ \\
\hline Shale & 2.35 & $\begin{array}{c}0.22 \sim 0.4 \\
(0.31)\end{array}$ & $1.83 \sim 3.97(2.9)$ & $9.8 \sim 98(53.9)$ & $1.9 \sim 9.8(5.8)$ & $\begin{array}{c}2.94 \sim 29.42 \\
(16.18)\end{array}$ \\
Sandstone & 2.45 & $\begin{array}{c}0.23 \sim 0.28 \\
(0.25)\end{array}$ & $2.44 \sim 4.25(3.3)$ & $19.6 \sim 137.2(78.4)$ & $3.9 \sim 24.5(14.2)$ & $\begin{array}{c}7.85 \sim 39.23 \\
(23.54)\end{array}$ \\
Limestone & 2.42 & 0.26 & 3.43 & $29.4 \sim 245(137.2)$ & $4.9 \sim 24.5(14.7)$ & $\begin{array}{c}9.81 \sim 49.03 \\
(29.42)\end{array}$ \\
Granite & 2.60 & 0.22 & 5.20 & $98 \sim 245(171.5)$ & $6.8 \sim 24.5(15.6)$ & $13.73 \sim 49.03$ \\
$(31.38)$
\end{tabular}

The data in parentheses is the value taken in this paper.

TABLE 2: The critical depth of the four types of rocks with auxiliary cut holes.

\begin{tabular}{lcccc}
\hline Inclination angle $\left({ }^{\circ}\right)$ & Shale $(\mathrm{m})$ & Sandstone $(\mathrm{m})$ & Limestone $(\mathrm{m})$ & $\mathrm{Granite}(\mathrm{m})$ \\
\hline 40 & 5.73 & 3.83 & 3.11 & 3.01 \\
4.78 \\
55 & 5.57 & 3.68 & 2.88 & 2.68 \\
50 & 5.37 & 3.48 & 2.72 & 2.54 \\
55 & 5.11 & 3.24 & 2.50 & 2.37 \\
60 & 4.77 & 2.91 & 2.21 & 1.84 \\
65 & 4.31 & 2.47 & 1.80 & 1.40 \\
70 & 3.65 & 1.95 & 1.50 & 0.90 \\
75 & 2.59 & 1.76 & & \\
\hline
\end{tabular}

The critical hole depths in the table are calculated under the condition that the 2\# rock emulsion explosive is used in four kinds of rocks.

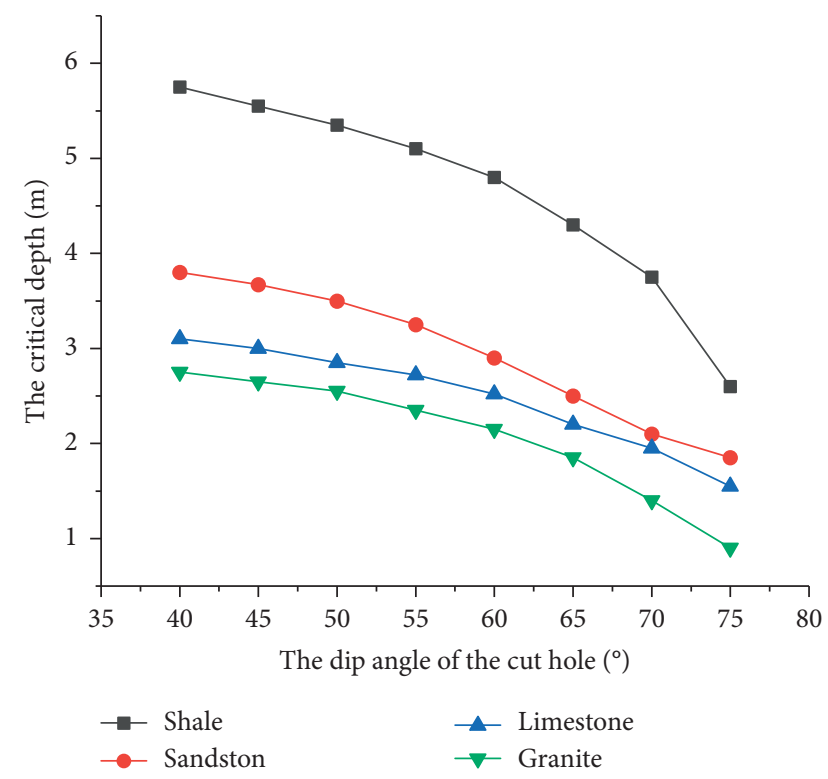

FIGURE 4: Relationships of critical depths and dip angles of the four types of rocks.

78.4 MPa, while all effective stresses in model I were below the dotted line. This means that the effective stress at the bottom of the cutting area is smaller than the compressive strength of sandstone. In other words, the rock in this area is barely broken after blasting, and the rock residues tend to exhibit a bulging phenomenon.

According to Figure 7, the maximum and average effective stresses in model I were $66 \mathrm{MPa}$ and $59.3 \mathrm{MPa}$, respectively, and those in model II were $133 \mathrm{MPa}$ and
118.1 MPa, respectively. Hence, the addition of auxiliary central holes increased the maximum and average effective stresses by $101.6 \%$ and $99.2 \%$, respectively. In addition, the auxiliary central holes also strengthened the cutting blasting stress field at the cavity bottom. Thanks to the clamping effect of the rock at the hole bottom, the rocks in this area are very unlikely to be broken and thrown out and tend to remain at the hole bottom. Furthermore, when hole depth and charging length meet certain requirements, an auxiliary central hole can improve the effective dynamic stress at the bottom of the cutting area and further enhance the crushing and throwing of the rock, making it possible to reach an ideal cutting depth and cavity shape.

In contrast, all effective stresses in model II were far above the dotted line, indicating that the effective stress at the bottom of the cut area far exceeds the compressive strength of rock. Thus, the rock masses in this area must be fragmented, thrown out, and separated from the surrounding rocks under the shock wave. This gives birth to a regular cavity. Hence, it is feasible to increase the cutting depth and improve the cuthole use with auxiliary central holes.

\section{Engineering Applications}

The study object is Banjie Tunnel in Southwest China's Yunnan Province. The physical-mechanical parameters of the surrounding rocks are given in Table 7 . The cuthole diameter $2 r_{\mathrm{a}}$ was $40 \mathrm{~mm}$, the cartridge diameter $2 r_{\mathrm{b}}$ was $32 \mathrm{~mm}$, and the $2 \#$ rock emulsion explosive was adopted for the blasting. The surrounding rock masses (grade III) were excavated by double horizontal V-cut with the 


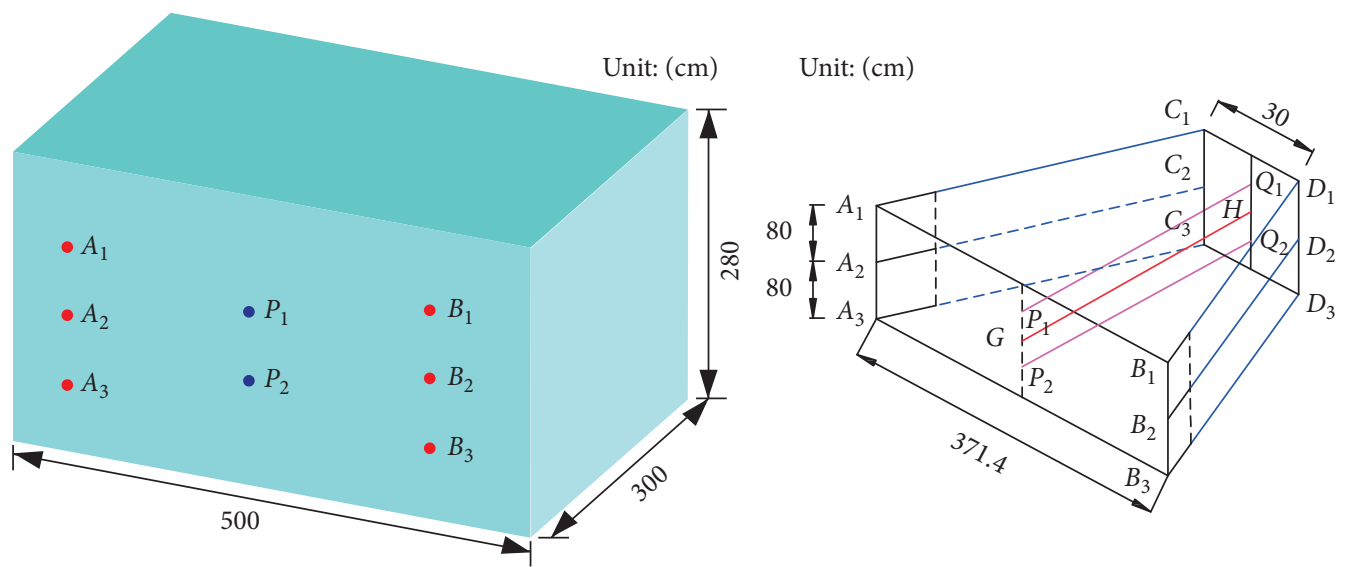

FIGURE 5: Numerical model and drilling hole pattern.

TABle 3: Material and state equation parameters of the rock (sandstone) [28].

\begin{tabular}{lccccc}
\hline Density $\left(\mathrm{kg} / \mathrm{m}^{3}\right)$ & Modulus of elasticity $(\mathrm{GPa})$ & Poisson ratio & Yield stress $(\mathrm{MPa})$ & Tangent modulus (GPa) & Hardening coefficient \\
\hline 2350 & 61.0 & 0.31 & 75.0 & 2.0 & 1.0 \\
\hline
\end{tabular}

TABle 4: Material and state equation parameters of the explosive [28].

\begin{tabular}{|c|c|c|c|c|c|c|c|c|c|}
\hline Density $\left(\mathrm{kg} / \mathrm{m}^{3}\right)$ & Explosion velocity $(\mathrm{m} / \mathrm{s})$ & Detonation pressure $(\mathrm{GPa})$ & $A(\mathrm{GPa})$ & $B(\mathrm{GPa})$ & $R_{1}$ & $R_{2}$ & $\omega$ & $E_{0}(\mathrm{GPa})$ & $V_{0}$ \\
\hline 1300 & 4000 & 5.2 & 211.4 & 0.182 & 4.2 & 0.9 & 0.15 & $4.192 E 6$ & 1.0 \\
\hline
\end{tabular}

$A, B, R_{1}, R_{2}$, and $\omega$ are material parameters; $R_{1}$ and $R_{2}$ are nondimensional parameters; $\omega$ is the Grüneisen parameter on the change rate of pressure relative to internal energy under constant volume; $E_{0}$ is the initial internal energy of a unit volume explosive; $V_{0}$ is the relative volume.

TABLE 5: Material and state equation parameters of the air [28].

\begin{tabular}{lccccccccc}
\hline Density $\left(\mathrm{kg} / \mathrm{m}^{3}\right)$ & $C_{0}$ & $C_{1}$ & $C_{2}$ & $C_{3}$ & $C_{4}$ & $C_{5}$ & $C_{6}$ & $E_{0}(\mathrm{GPa})$ & $V_{0}$ \\
\hline $1.29 \times 10^{-2}$ & 0 & 0 & 0 & 0 & 0.4 & 0.4 & 0 & 0 & 1.0 \\
\hline
\end{tabular}

$A_{0}, A_{1}$, and $A_{2}$ are yield function constants; PC is the truncation pressure of tensile failure; EPS1 EPS 10 are the characteristic bulk strains; $P_{1} \sim P_{10}$ are the pressures corresponding to characteristic bulk strains.

vertical hole depth being $4 \mathrm{~m}$. The cuthole arrangement is shown in Figure 8.

Using the double horizontal V-cut, the tunnel advanced about $3.33 \mathrm{~m}$ per cycle, only $83 \%$ of cutholes were utilized, and the specific charge was $0.976 \mathrm{~kg} / \mathrm{m}^{3}$. As shown in Figure 9, the blasting failed to meet the construction criteria in that the rock fragments were unevenly distributed large boulders. The construction criteria specify that the monthly advancement in grade III rock should be $110 \mathrm{~m}$, that is, $3.7 \mathrm{~m}$ per day. Due to the poor blasting effect and limited cyclic advancement, it is virtually impossible to make further advancement following the original design.

Considering the construction schedule, the driving cycle should be $4 \mathrm{~m}$ in grade III surrounding rocks. The vertical hole depth should increase to $4.5 \mathrm{~m}$ so as to utilize $90 \%$ of cutholes. Hence, the cuthole depth was designed as $4.7 \mathrm{~m}$, $0.1 \sim 0.2 \mathrm{~m}$ deeper than the normal hole. According to the size of the tunnel section, $\mathrm{V}$-cut blasting holes were adopted. The cutting blasting parameters were calculated with the dip angle of $60^{\circ}$ and corresponding hole length $L$ of $5.4 \mathrm{~m}$.
For Banjie Tunnel, the hole bottom spacing $a=158 \mathrm{~mm}$, the row spacing of the cuthole $d_{1}=0.819 \mathrm{~m}$, the charging coefficient $k=1.232$, and the charging length $l_{e}=6.87 \mathrm{~m}$. In this case, the charging length $l_{e}>0.75\left(H / \sin \theta+H_{i} / \sin \theta_{i}\right)$, an evidence for the need of both auxiliary central holes and shallow inclined holes. The vertical depth of each auxiliary inclined hole was $2.4 \mathrm{~m}$ and the dip angle was $45^{\circ}$.

Similarly, the vertical depth of the cut blasting hole was designed as $2.9 \mathrm{~m}$ for grade IV surrounding rocks, and the hole length $L$ was $3.8 \mathrm{~m}$ at the dip angle of $50^{\circ}$. Following the above theoretical solution, the hole bottom spacing $a$ was calculated as $175 \mathrm{~mm}$, the row spacing $d_{1}$ was $0.888 \mathrm{~m}$, and the charging coefficient $k$ was 0.64 . Since the charging coefficient $k$ was smaller than the critical charge coefficient (0.75), no auxiliary cuthole is needed.

At the construction site, the actual hole bottom spacing $a$ was $0.2 \mathrm{~m}$, and row spacing $d_{1}$ was $0.8 \mathrm{~m}$ for grade III rocks; the hole bottom spacing and row spacing were $0.2 \mathrm{~m}$ and $0.88 \mathrm{~m}$, respectively, for grade IV rocks. The cuthole arrangements in grade III and grade IV surrounding rocks are 


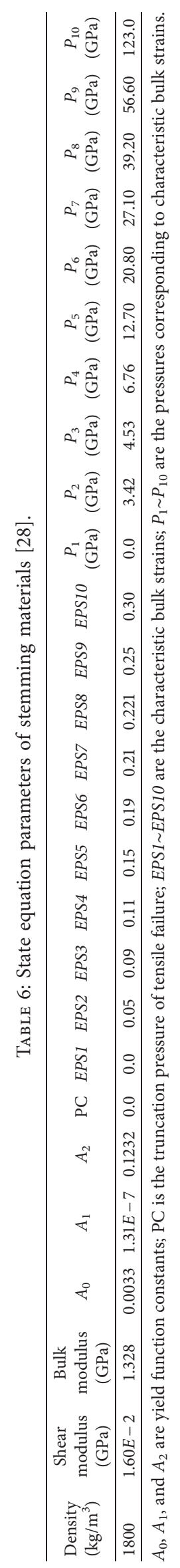



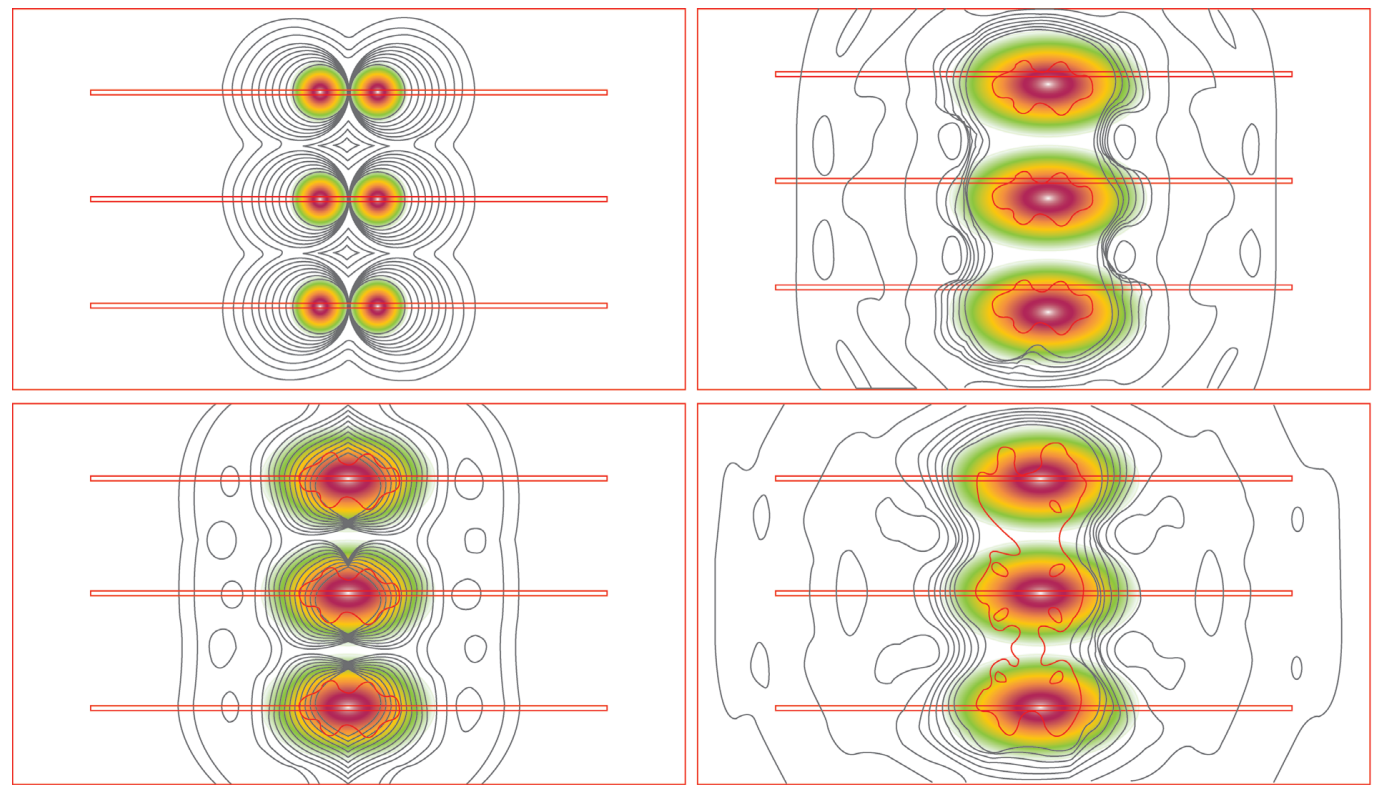

Fringe levels

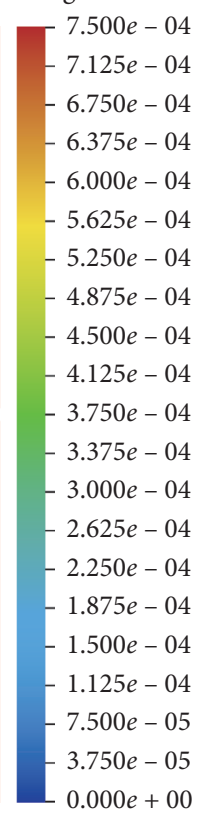

Figure 6: Contours of typical explosive effective stress at different stages after detonation.

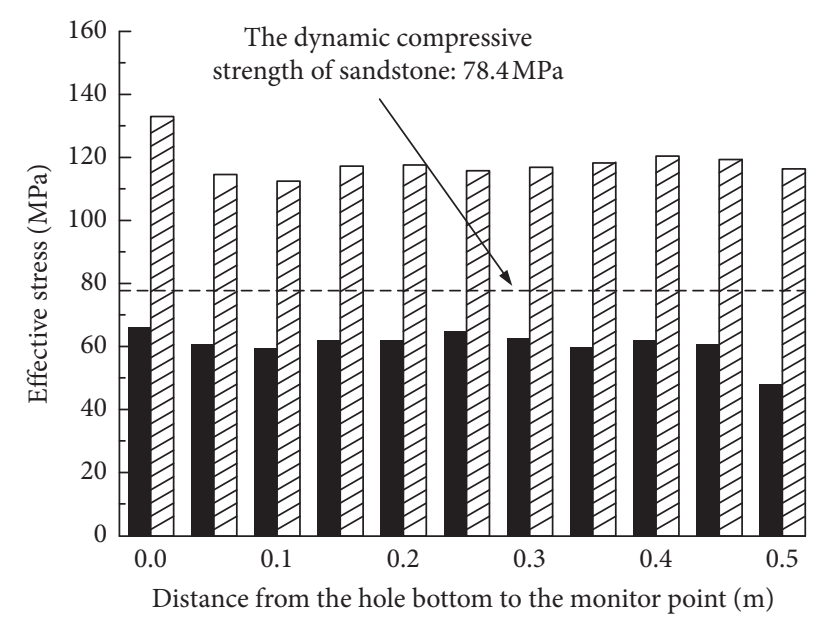

Model I

피 Model II

FIGURE 7: Distributions of effective stress in the two models.

TABLE 7: Physical-mechanical parameters of the surrounding rocks.

\begin{tabular}{lcccccc}
\hline $\begin{array}{l}\text { Surrounding rock } \\
\text { grade }\end{array}$ & $\begin{array}{c}\text { Density } \\
\left(\mathrm{kg} / \mathrm{m}^{3}\right)\end{array}$ & $\begin{array}{c}\text { Compressive strength } \\
(\mathrm{MPa})\end{array}$ & $\begin{array}{c}\text { Tensile strength } \\
(\mathrm{MPa})\end{array}$ & $\begin{array}{c}\text { Shear strength } \\
(\mathrm{MPa})\end{array}$ & $\begin{array}{c}\text { Longitudinal wave } \\
\text { velocity }(\mathrm{m} / \mathrm{s})\end{array}$ & $\begin{array}{c}\text { Static Poisson } \\
\text { ratio }\end{array}$ \\
\hline III & 2700 & 75 & 5.6 & 23.3 & 3350 & 0.23 \\
IV & 2600 & 60 & 5.0 & 18.6 & 3200 & 0.23 \\
\hline
\end{tabular}

presented in Figure 10, and the cutting blasting parameters for grade III rocks are given in Table 8 .

The specified cutting method was consistently used in the excavation of Banjie Tunnel. The technical statistics of cutting blasting in grade III rocks are listed in Table 9 and the field blasting effect is shown in Figure 11. The results of quasiparallel cutting indicate that the blasting effect was moderately improved with the addition of auxiliary central holes or shallow 


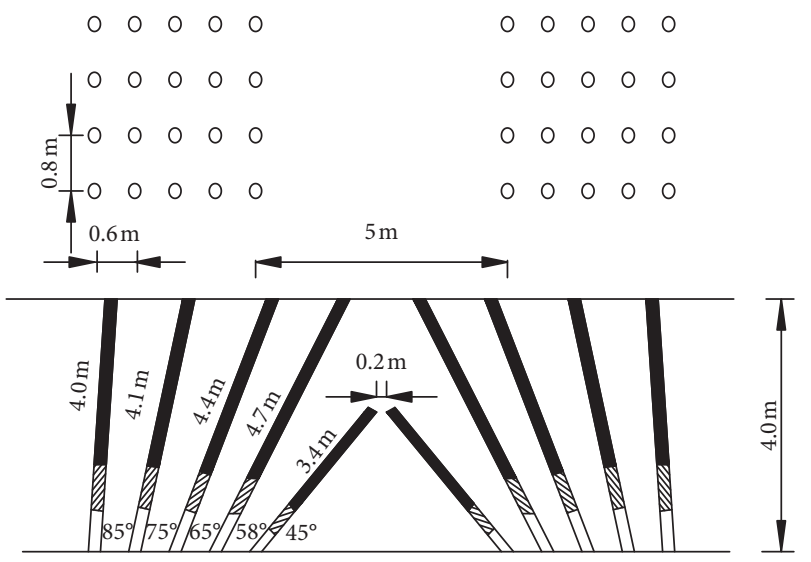

FIGURE 8: The arrangement of cutholes in excavation of surrounding rock masses (grade III).

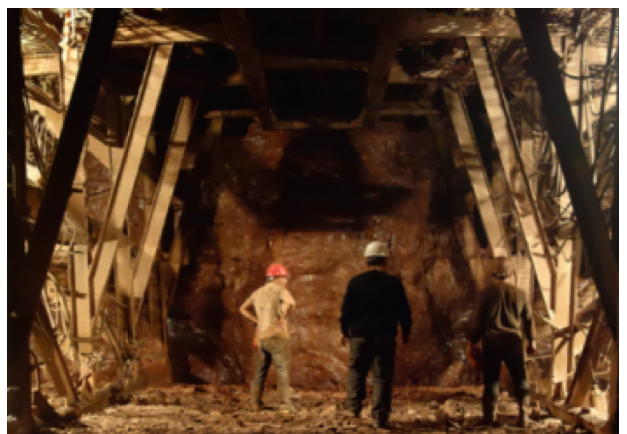

(a)

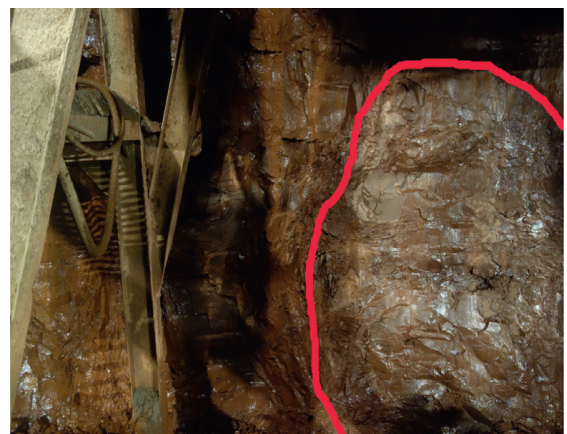

(b)

FIGURE 9: Blasting effect of double horizontal V-cut blasting.

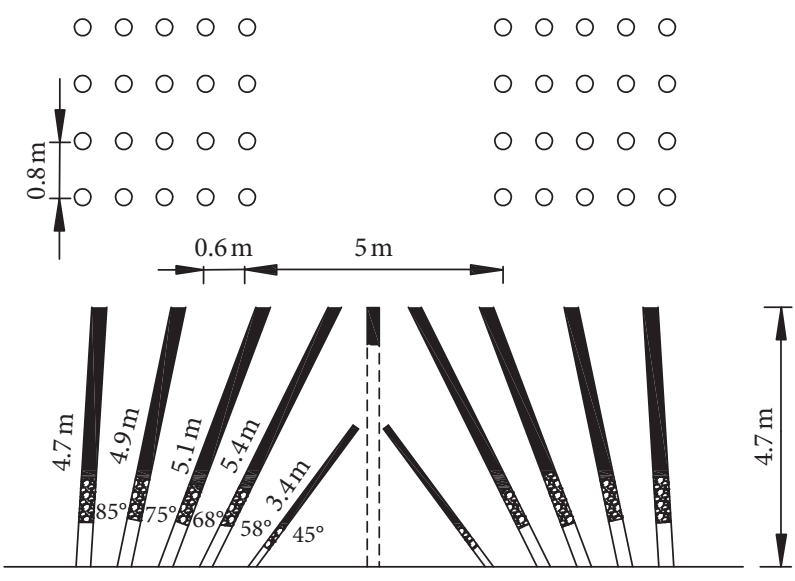

(a)

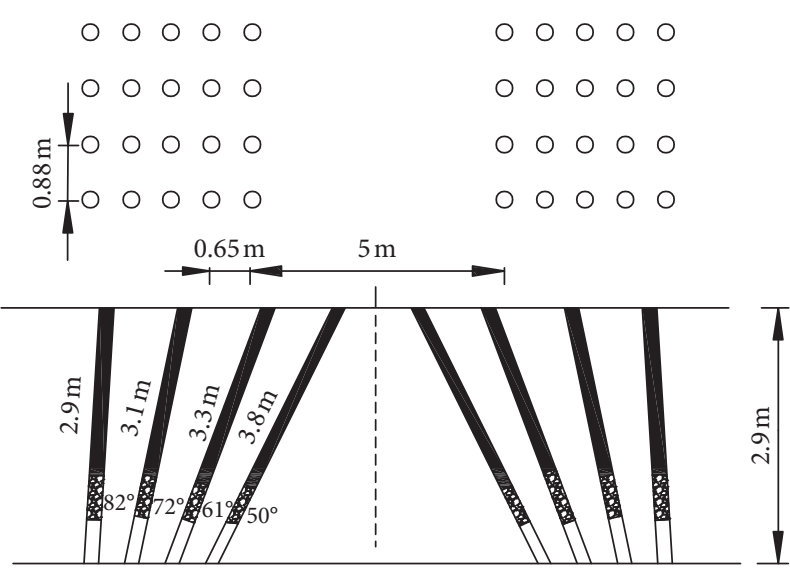

(b)

FIGURE 10: Cuthole arrangement in (a) grade III (arrangements of cutting holes in class III rocks) and (b) grade IV rocks (arrangements of cutting holes in class IV rocks). 
TABLE 8: Cutting blasting parameters in grade III rocks [32].

\begin{tabular}{|c|c|c|c|c|c|c|}
\hline \multirow{2}{*}{\multicolumn{2}{|c|}{ Hole type }} & \multirow{2}{*}{ Number of holes } & \multirow{2}{*}{ Segments of detonators } & \multirow{2}{*}{ Hole depth (m) } & \multicolumn{2}{|c|}{ Charge quantity (kg) } \\
\hline & & & & & Single hole & Total \\
\hline \multirow{6}{*}{ Cuthole } & First wedge & 8 & 1 & 3.3 & 2.40 & 19.20 \\
\hline & Second wedge & 8 & 3 & 5.4 & 4.00 & 32.00 \\
\hline & Central hole & 3 & 3 & 4.9 & 0.60 & 1.80 \\
\hline & Third wedge & 8 & 5 & 5.1 & 3.80 & 30.40 \\
\hline & Fourth wedge & 8 & 7 & 4.9 & 3.60 & 28.80 \\
\hline & Fifth wedge & 8 & 9 & 4.7 & 3.50 & 28.00 \\
\hline \multicolumn{2}{|c|}{ Auxiliary hole } & 30 & $11 \sim 13$ & 4.7 & 2.25 & 67.50 \\
\hline \multicolumn{2}{|c|}{ Periphery hole } & 40 & 14 & 4.7 & 0.90 & 36.00 \\
\hline \multicolumn{2}{|c|}{ Bottom hole } & 15 & 15 & 4.7 & 2.40 & 36.00 \\
\hline \multicolumn{2}{|c|}{ Total } & 128 & & & & 279.70 \\
\hline
\end{tabular}

TABLE 9: Technical statistics of V-cut blasting with auxiliary holes.

\begin{tabular}{lcccc}
\hline Date & Vertical depth of hole $(\mathrm{m})$ & Cyclic advancement $(\mathrm{m})$ & Blasthole utilizing factor $(\%)$ & Specific charge $\left(\mathrm{kg} / \mathrm{m}^{3}\right)$ \\
\hline 2019.3 .18 & 4.7 & 4.29 & 91.4 & 0.882 \\
2019.3 .19 & 4.7 & 4.27 & 90.8 & 0.886 \\
2019.3 .20 & 4.7 & 4.20 & 89.4 & 0.900 \\
2019.3 .21 & 4.7 & 4.25 & 90.4 & 0.891 \\
2019.3 .22 & 4.7 & 4.29 & 91.2 & 0.882 \\
2019.3 .23 & 4.7 & 4.23 & 90.6 & 0.895 \\
2019.3 .24 & 4.7 & 4.26 & 90.5 & 0.886 \\
Average & 4.7 & 4.26 & 0.889 \\
\hline
\end{tabular}

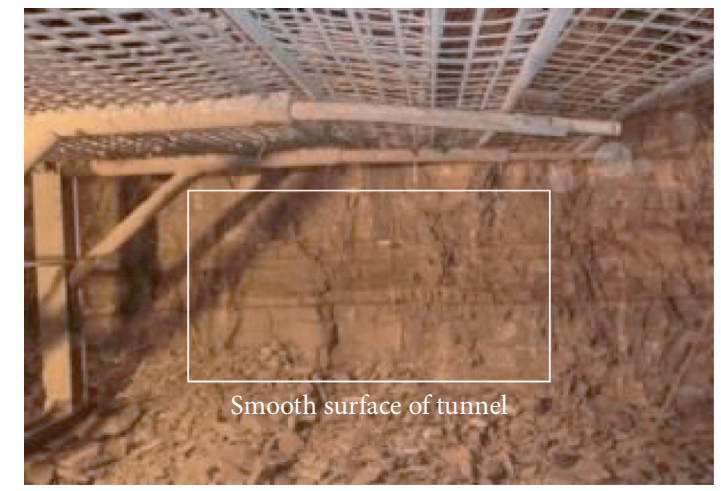

FIgURE 11: Effect of V-cut blasting with auxiliary holes.

cutholes. The advancement per cycle increased by $27 \%$, and the cuthole utilization ratio climbed up from $83 \%$ to over $90 \%$.

\section{Conclusion}

Based on the $\mathrm{V}$-cut blasting mechanism hypothesis, this paper analyzes the formation process of the cut blasting cavity, deduces the theoretical formula of each cut blasting parameter, proposes a calculation method for increasing the critical depth of the central hole, and calculates the value based on the charge length coefficient. Differences in the various types of auxiliary cutholes were proposed. Combining numerical simulation and field industrial test verification, it is concluded that when the rock attributes, explosive properties, and the cuthole dip angle are constant, the hole increasing criteria for various types of cutholes are as follows:

(1) When the charge length satisfies $l_{e}<0.75 H / \sin \theta$, there is no need to increase the slot.

(2) When the charge length satisfies $0.75 H / \sin \theta<l_{e}<$ $0.75 \mathrm{H} / \sin \theta+(2 \sim 4) \times 0.1$, the center vertical hole needs to be added.

(3) When the charge length satisfies $0.75 H / \sin \theta+(2 \sim$ 4) $\times 0.1<l_{e}<0.75\left(\mathrm{H} / \sin \theta+H_{i} / \sin \theta_{i}\right)$, a shallow hole with a shallow depth needs to be added.

(4) When the length of the charge satisfies $l_{e}<0.75(\mathrm{H} /$ $\left.\sin \theta+H_{i} / \sin \theta_{i}\right)$, it is necessary to add a central hole and a shallow inclined hole. 


\section{Data Availability}

All data and models generated or used during the study appear in the submitted article.

\section{Conflicts of Interest}

The authors declare that there are no conflicts of interest regarding the publication of this paper.

\section{Acknowledgments}

This research is supported by the National Natural Science Foundation of China (Grants nos. 51679093 and 51374112).

\section{References}

[1] G. W. Ma and X. M. An, "Numerical simulation of blastinginduced rock fractures," International Journal of Rock Mechanics and Mining Sciences, vol. 45, no. 6, pp. 966-975, 2008.

[2] Z. L. Wang and H. Konietzky, "Modelling of blast-induced fractures in jointed rock masses," Engineering Fracture Mechanics, vol. 76, no. 12, pp. 1945-1955, 2009.

[3] S. H. Cho and K. Kaneko, "Influence of the applied pressure waveform on the dynamic fracture processes in rock," International Journal of Rock Mechanics and Mining Sciences, vol. 41, no. 5, pp. 771-784, 2004.

[4] Z. Zhu, H. Xie, and B. Mohanty, "Numerical investigation of blasting-induced damage in cylindrical rocks," International Journal of Rock Mechanics and Mining Sciences, vol. 45, no. 2, pp. 111-121, 2008.

[5] Y. S. Stepanov, "Maximum fracture zone in solid rock due to explosion of two parallel cylindrical charges," Soviet Mining Science, vol. 10, no. 6, pp. 672-674, 1974.

[6] J. Guo, D. Q. Gan, J. Tan, and G. L. Lv, "The dynamic effect analysis of transient unloading due to blasting excavation in deep and hard rock roadway," Advanced Materials Research, vol. 753-755, pp. 682-685, 2013.

[7] V. Y. Shaprio, "Efficiency of cut configuration in driving tunnels with a set of deep blast holes," Soviet Mining Science, vol. 25, no. 4, pp. 379-386, 1989.

[8] K. Soroush, Y. Mehdi, and E. Arash, "Trend analysis and comparison of basic parameters for tunnel blast design models," International Journal of Mining Science and Technology, vol. 25, no. 4, pp. 595-599, 2015.

[9] R. L. Shan, B. L. Huang, W. J. Gao, Y. Zhu, and X. Y. Hao, "Case studies of new technology application of quasi-parallel cut blasting in rock roadway drivage," Chinese Journal of Rock Mechanics and Engineering, vol. 30, no. 2, pp. 224-232, 2011.

[10] W. Chen, H. H. Ma, Z. W. Shen, and D. B. Wang, "Highefficiency cut blasting with shell radial shaped charge in laboratory-scale blasting," Advanced Materials Research, vol. 1094, pp. 445-450, 2015.

[11] Y.-p. Zhang, C.-l. Weng, and E.-a. Chi, "A new method of cutblasting for vertical shaft excavation and its experimental study," Journal of Coal Science and Engineering (China), vol. 16, no. 1, pp. 17-22, 2010.

[12] J.-G. Kim and J.-J. Song, “Abrasive water jet cutting methods for reducing blast-induced ground vibration in tunnel excavation," International Journal of Rock Mechanics and Mining Sciences, vol. 75, pp. 147-158, 2015.

[13] L. X. Xie, W. B. Lu, Q. B. Zhang, Q. H. Jiang, M. Chen, and J. Zhao, "Analysis of damage mechanisms and optimization of cut blasting design under high in-situ stresses," Tunnelling and Underground Space Technology, vol. 66, pp. 19-33, 2017.

[14] R. S. Yang, Y. L. Che, X. Tong, Y. L. Mi, and L. Feng, "Experimental study on the technology of middle empty hole in parallel hole cut blasting," Advanced Materials Research, vol. 594-597, pp. 1314-1317, 2012.

[15] Y. P. Liu, J. H. Li, D. N. Lin, and S. R. Chen, "Theoretical and experimental study on effects of empty hole in cut blasting," Mining Research and Development, vol. 27, no. 5, pp. 75-77, 2007.

[16] G. L. Yang, L. L. Jiang, and R. S. Yang, "Investigation of cut blasting with duplex wedge deep holes," Journal of China University of Mining and Technology, vol. 42, no. 5, pp. 755-760, 2013.

[17] S. Qu, X. Zheng, L. Fan, and Y. Wang, "Numerical simulation of parallel hole cut blasting with uncharged holes," Journal of University of Science and Technology Beijing, Mineral, Metallurgy, Material, vol. 15, no. 3, pp. 209-214, 2008.

[18] M. Gong, B. Wen, and H. Wang, "Influences of cut parameters on blasting effect in rock roadway of coal mine," Explosion and Shock Waves, vol. 35, no. 4, pp. 576-584, 2015.

[19] V. Y. Shapiro, A. V. Korn, and I. N. Pochtar', "Choice of parameters for explosive destruction of rock based on operational information on the composition of the rock," Soviet Mining Science, vol. 25, no. 2, pp. 131-136, 1989.

[20] V. A. Bezmaternykh, P. A. Lykhin, N. N. Leshchukov, and V. M. Mal'tsev, "Determining the parameters of a set of blasthole charges," Soviet Mining Science, vol. 11, no. 6, pp. 670-673, 1975.

[21] Y. C. Owe and I. G. O, "A grey relation analysis of main parameters affecting on V-cut blasting efficiency," Chaegulkonghak (Ming Engineering), vol. 95, no. 1, pp. 13-15, 2006.

[22] A. P. Andrievskii, "Calculation of optimal parameters for drilland-blast operation chart in mining with direct slot stage cutting," Journal of Mining Science, vol. 28, no. 5, pp. 456-461, 1993.

[23] W. Qiao, K. Huang, M. Azimi, and S. Han, "A novel hybrid prediction model for hourly gas consumption in supply side based on improved whale optimization algorithm and relevance vector machine," IEEE Access, vol. 7, no. 7, pp. 88218-88230, 2019.

[24] W. Qiao, W. Tian, Y. Tian, Q. Yang, Y. Wang, and J. Zhang, "The forecasting of PM2.5 using a hybrid model based on wavelet transform and an improved deep learning algorithm," IEEE Access, vol. 7, no. 7, pp. 142814-142825, 2019.

[25] X. Lou, P. Zhou, Y. Jin et al., "Analysis on the impact pressure on blast hole wall with radial air-decked charge based on shock tube theory," Soil Dynamics and Earthquake Engineering, vol. 128, Article ID 105905, 2020.

[26] X. Lou, Z. Wang, B. Chen et al., "Theoretical calculation and experimental analysis on initial shock pressure of borehole wall under axial decoupled charge," Shock and Vibration, vol. 2018, Article ID 7036726, 14 pages, 2018.

[27] J. Yan, Research on Over-or-under Excavation Control of Tunnels in Tuff Layer with Developed Cutters, Central South University, Changsha, China, 2012.

[28] J. Dai, Dynamic Behaviors and Blasting Theory of Rock, Metallurgical Industry Press, Beijing, China, 2013.

[29] K. O. Hakalehto, "Brittle fracture of rocks under impulse loads," International Journal of Fracture Mechanics, vol. 6, no. 3, pp. 249-256, 1970.

[30] X. G. Wang, Handbook of Blasting, Metallurgical Industry Press, Beijing, China, 2010.

[31] Split Bar Method, Technical University, Otaniemi-Helsinki, Acta Polytechnica Scandinanca, 1987.

[32] Geological Survey Report of Banjie Tunnel, China Railway Fourth Survey and Design Institute, Liuzhou, China, 2016. 